\title{
ANALISA INDEX VEGETASI NDVI DAN MCARI UNTUK PENENTUAN TUTUPAN LAHAN SAWAH Studi Kasus: Kabupaten Karawang
}

\author{
Hisyam Wardana Y, Bangun Mulyo Sukojo, Udiana Wahyu \\ Program Studi Teknik Geomatika FTSP-ITS, Kampus ITS Sukolilo, Surabaya, 60111 \\ Email : bangunms@gmail.com,diana_deviantari@yahoo.com
}

\begin{abstract}
Abstrak
Penginderaan jauh merupakan suatu ilmu atau teknologi untuk memperoleh informasi atau fenomena alam melalui analisis suatu data yang diperoleh dari hasil rekaman obyek, daerah ataufenomena yang dikaji. Perekaman atau pengumpulan data penginderaan jauh (inderaja) dilakukan dengan menggunakan alat pengindera (sensor) yang dipasang pada pesawat terbang atau satelit.Teknologi penginderaan jauh dapat menjadi solusi untuk pendeteksian tutupan lahan sawah untuk suatuwilayah yang cukup luas sehingga dibutuhkan waktu yang cepat. Airborne Hyperspektral merupakansalah satu metode penginderaan jauh yang dapat memberikan data informasi yang banyak karena terdiridari kanal yang banyak dan sempit.Dalam penelitian ini dilakukan dengan menggabungkan datahasil pemotretan dari pesawatmenggunakan data Airborne Hyperspectral di Kabupaten Indramayu Jawa Barat dengan data hasilground truth di lapangan. Dengan data ini akan dilakukan analisa pemetaan tutupan lahan sawah untukmengetahui areal persawahan yang terdapat di Kabupaten Karawang
\end{abstract}

Kata Kunci : Padi, Hymap, Nilai NDVI, Korelasi.

\section{PENDAHULUAN}

Untuk mengetahui kondisi dan serta perubahan lahan pertanian diperlukan data-data penunjang antara lain peta tutupan lahan. Peta tutupan lahan adalah peta yang memberikan informasi mengenai objek-objek yang tampak di permukaan bumi (Campbel,1987). Ketepatan informasi tutupan lahan akan memberikan kemudahan dalam melakukan analisa perencanaan dan pengembangan suatu wilayah.

Kabupaten Karawang merupakan salah satu lumbung padi di Jawa Barat. Dari luas wilayah Kabupaten Karawang yaitu 1.753,27 kilometer persegi atau 175.327 hektar (sekitar 4 persen dari total luas wilayah Propinsi Jawa Barat), luas areal pertaniannya yaitu 94.311 hektar.

Dalam era globalisasi, kebutuhan akan informasi dalam program ketahanan pangan sangat dibutuhkan. Oleh sebab itu, sangat diperlukan teknologi yang mendukung dalam mendapatkan informasi. Teknologi penginderaan jauh adalah suatu teknologi yang dapat dimanfaatkan dalam berbagai aplikasi yang diinginkan (Barret dan Curtis, 1982).
Pemanfaatan citra satelit dengan resolusi spasial yang tinggi sangat diperlukan di daerah perkotaan yang mempunyai tingkat keragaman tutupan lahan yang heterogen (Lillesand dkk, 1994) Dengan ini dilakukan penelitian tentan gtutupan lahan sawah kita dapat mengetahui estimasi produksi sawah tiap tahunnya dan memberikan informasi spasial berupa peta

\section{METODOLOGI PENELITIAN}

Pada penelitian ini area studi yang digunakan adalah wilayah Kabupaten Karawang, Jawa Barat

a. Lokasi Penelitian 


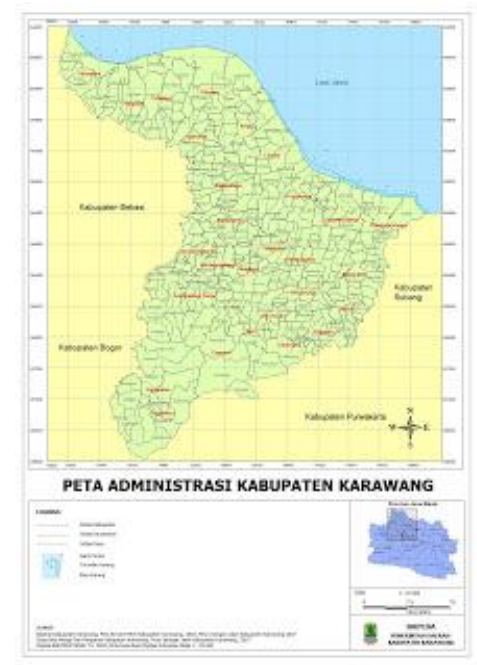

Gambar 1.Lokasi penelitian

(Sumber: Pemerintah Kabupaten Karawang Badan Perencanaan Pembangunan Daerah 2009)

b. Data Penelitian

Data yang digunakandalampenelitianiniantara lain adalah Citra HyMap Kabupaten Karawang tahun 2011 dan data fieldspektrometer serta data groundtruh yang diambil pada bulan November 2013 menggunakan GPS handheld .

Berdasarkan diagram alir dibawah, secara umum penelitian ini dibagi menjadi tahapan sebagai berikut:

1. Pengolahan citra HYMAP yang meliputi proses koreksikesalahan geometrikdanKesalahanAtmosferikwilayah Kabupaten Karawang.

2. Pengolahan data menggunakan index vegetasi

3. Mengkorelasikan data Nilai NDVI dan MCARI dengan data fieldspectrometer

4. KlasifikasiSupervised untuk mengetahui tutupan lahan di Kabupaten Karawang

5. Intersect untuk menggabungkan hasil pengolahan index vegetasi dengan hasil klasifikasi supervised

6. Uji ketelitian klasifikasi

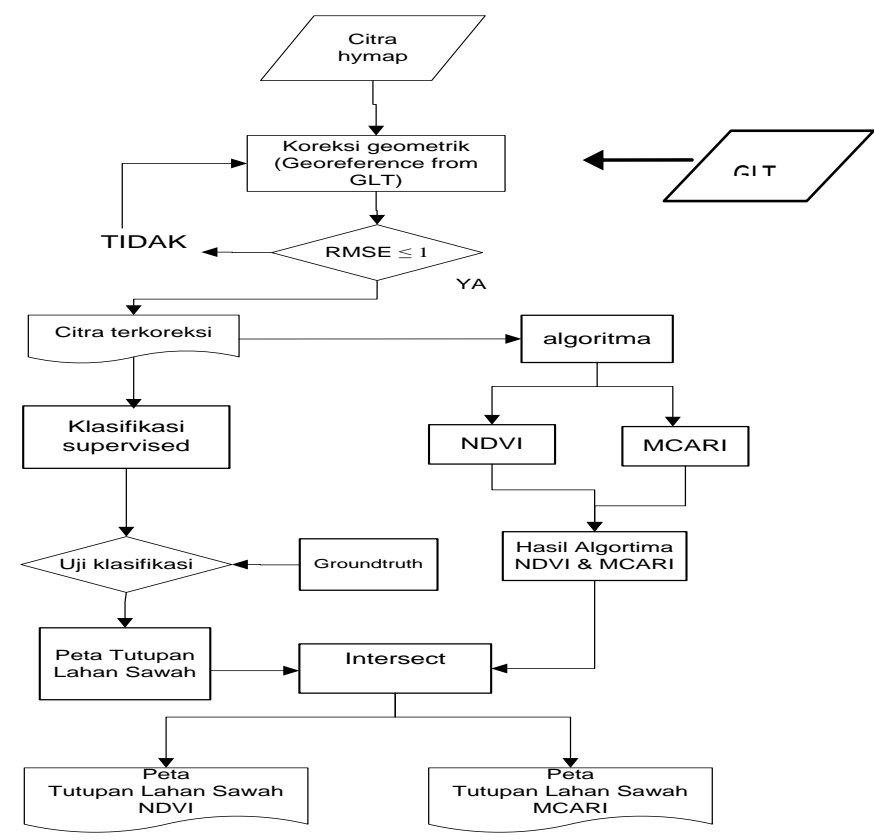

Gambar 2. Diagram AlirPengolahan Data

\section{d. NDVI(Normalized Difference Vegetation Index)}

Indeks vegetasi adalah besaran nilai kehijauan vegetasi yang diperoleh dari pengolahan sinyal dijital data nilai kecerahan (brightnes) beberapa kanal sensor satelit. Untuk pemantauan vegetasi, dilakukan proses pembandingan antara tingkat kecerahan kanal cahaya merah (red) dan kanal cahaya inframerah dekat (near infrared).

Fenomena penyerapan cahaya merah oleh klorofil dan pemantulan cahaya infaramerah dekat oleh jaringan mesofil yang terdapat pada daun akan membuat nilai kecerahan yang diterima sensor satelit pada kanal-kanal tersebut akan jauh berbeda. Pada daratan non-vegetasi, termasuk diantaranya wilayah perairan, pemukiman penduduk, tanah kosong terbuka, dan wilayah dengan kondisi vegetasi yang rusak, tidak akan menunjukkan nilai rasio yang tinggi (minimum). Sebaliknya pada wilayah bervegetasi sangat rapat, 
dengan kondisi sehat, perbandingan ke dua kanal tersebut akan sangat tinggi (maksimum).

AlgoritmaNormalized difference Vegetation Index (NDVI)(Rouse et al., 1974 in Hariyadi,1999) adalah:

$$
N D V I=\frac{\rho I R-\rho R E D}{\rho I R+\rho R E D}
$$

e. MCARI (Modified Clorophyl Ratio Absortion Index)

MCARI merupakan salah satu indeks vegetasi yang digunakan untuk menentukan indeks vegetasi, rumusnya sebagai berikut :

MCARI $[670,700]=[(R 700-R 670)-0.2(R 700-$

$\mathrm{R} 550)]\left(\frac{R 700}{R 670}\right)$

MCARI adalah pengembangan dari index vegetasi CARI oleh (Daughtry, 2000).

\section{HASIL DAN PEMBAHASAN}

A. Hasil Koreksi Geometrik Citra HyMap Koreksi geometrik dilakukan pada setiap lajur dari citra HyMap dengan menggunakan Geometric Lookup Table (GLT) yaitu sebuah metode pengkoreksian pada setiap piksel untuk penentuan posisi geospasial dari lintang dan bujur pada suatu area. Dari proses koreksi geometrik pada setiap lajur didapatkan nilai RMS Error kurang dari 1 pixel sebagai berikut:

Tabel 1. RMS Error tiap lajur

\begin{tabular}{ll}
\hline No. Lajur & RMS Error \\
\hline 1 & 0.455 \\
2 & 0.148 \\
3 & 0.061 \\
4 & 0.134 \\
5 & 0.143 \\
6 & 0.086 \\
7 & 0.028 \\
8 & 0.307 \\
9 & 0.203 \\
10 & 0.112 \\
\hline
\end{tabular}
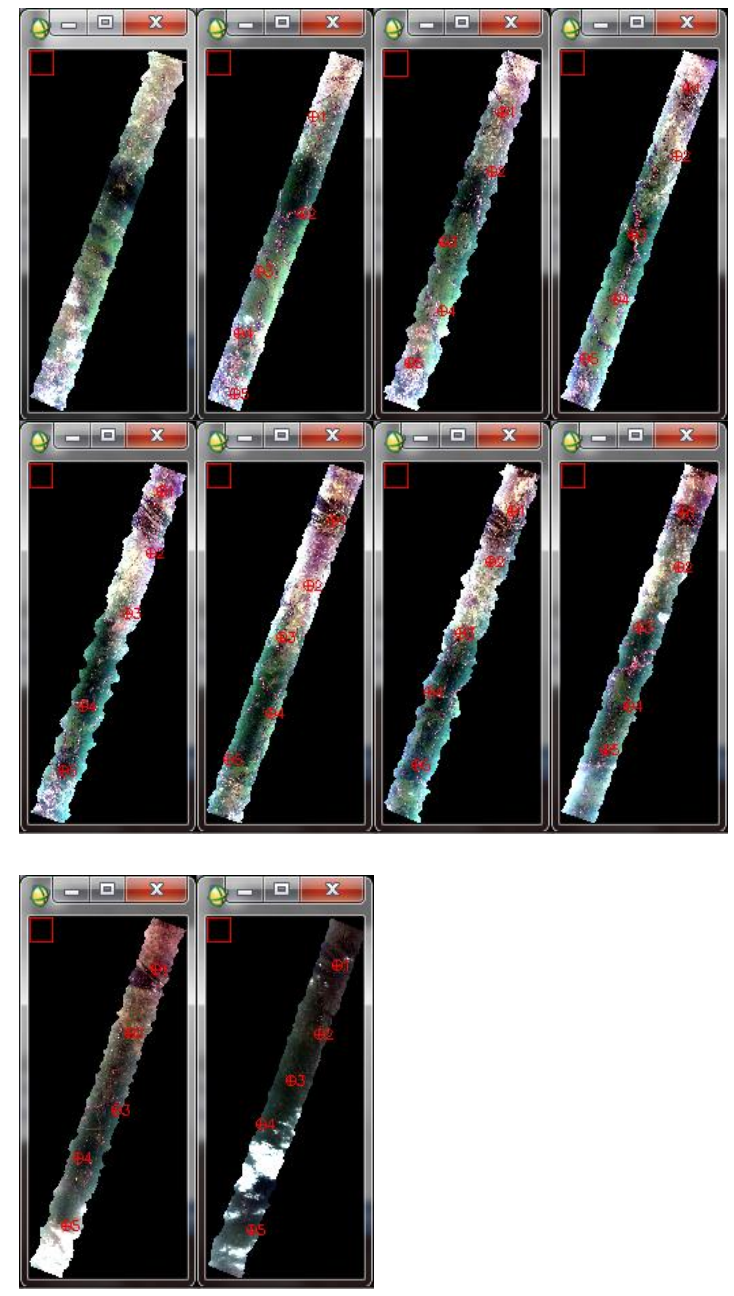

B. Pengolahan algoritma NDVI dan MCARI dilakukan untuk membandingkan kedua index vegetasi ini dalam mendeteksi luasan sawah yang ada di kabupaten karawang ,hasilnya seperti berikut ini :

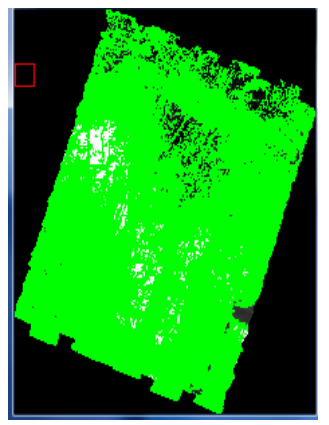

Gambar 1. Menggunakan index vegetasi NDVI 


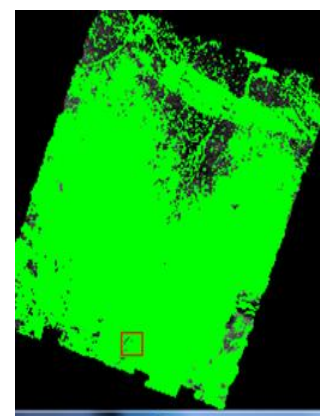

Gambar 2. Menggunakan index vegetasi MCARI

C. Korelasi Nilai NDVI dan MCARI Citra dengan data Field Spectrometer

Analisa ketelitian indeks vegetasi dilakukan untuk mengetahui ketelitian dari masing masing indeks vegetasi,untuk menganalisa ketelitian indeks vegetasi digunakan data field spectrometer untuk di korelasikan dengan nilai indeks vegetasi NDVI dan MCARI.Dari hasil korelasi didapat indeks vegetasi NDVI adalah 0,7871 dan indeks vegetasi MCARI 0,6821, hasil ini cukup baik karena pada literatur yang telah ada nilai 0,7871 dan 0,6431 nilainya sangat kuat,korelasi ini pernah dilakukan oleh Fuad tahun 2013 dan nilainya juga sangat kuat yaitu 0,80 .

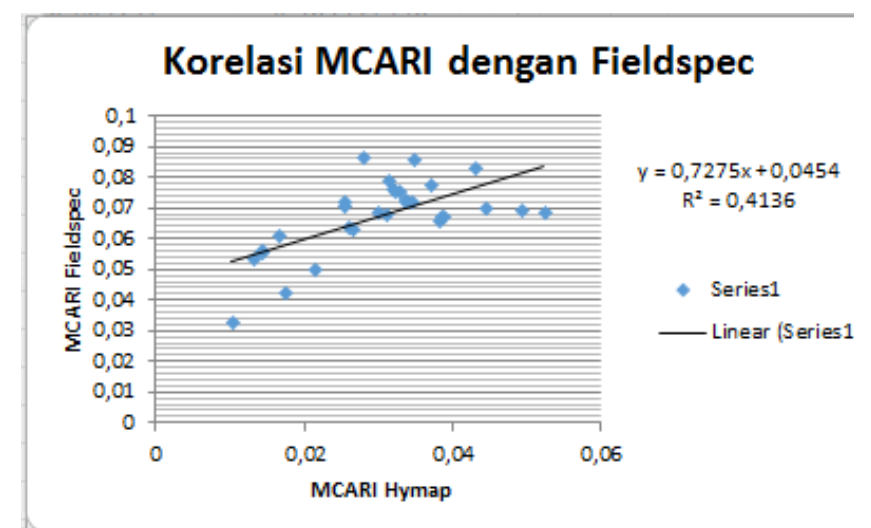

Gambar 3. Hubungan Nilai MCARIHymap Dengan data Fieldspectrometer

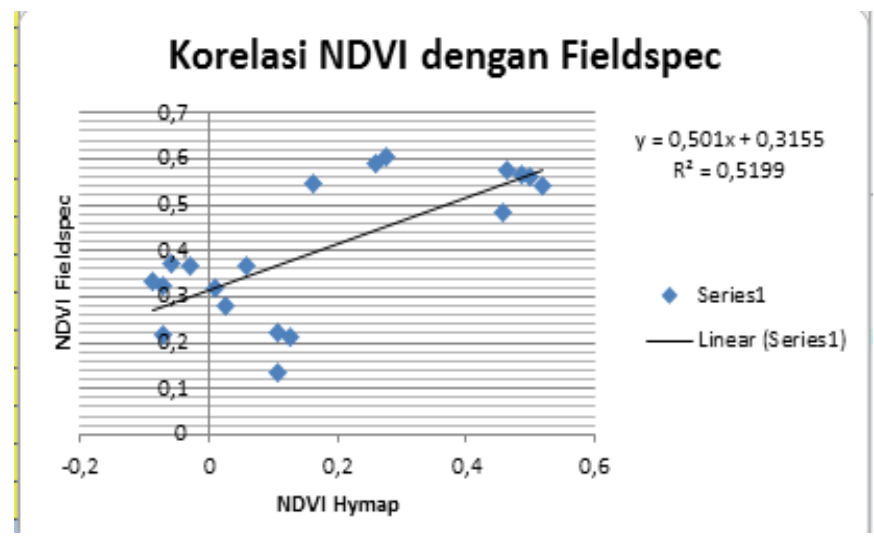

Gambar 4. Hubungan Nilai NDVI Hymap Dengan data Fieldspectrometer

Pada gambar 4 ditunjukkan bahwa NDVI hymap memiliki hubungan yang kuat terhadap nilai NDVI Field Spectrometer dibanding dengan MCARI hymap ditunjukkan dengan nilai koefisien determinasi yang cukup $R^{2}=0,5199$.

D. Klasifikasi Supervised untuk mengetahui tutupan lahan

Pekerjaan klasifikasi dilakukan dengan metode klasifikasi terbimbing dengan metode maximum likellihood. Jumlah kelas yang digunakan sejumlah 4 kelas tutupan lahan yaitu seperti dijelaskan dalam tabel di bawah ini:

Tabel 2.KelasTutupanLahan

\begin{tabular}{ccc}
\hline No & Kelas & Warna \\
\hline 1 & bangunan & \\
2 & sawah & \\
3 & Badan air & \\
4 & vegetasi & \\
\hline
\end{tabular}

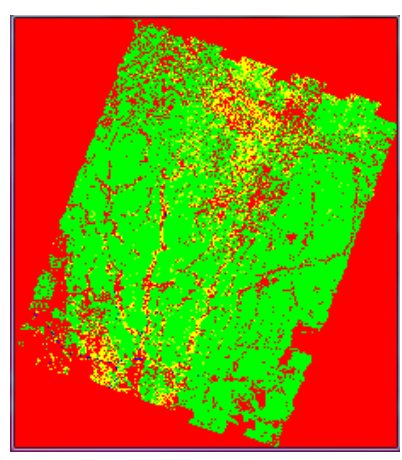

Gambar 5. Hasil klasifikasi Supervised 
Klasifikas terbimbing dengan metode maximum likelihood pada citra Airborne Hyper spectral bulan juni 2011 dengan sample area menghasilkan informasi yang dibutuhkan dalam bentuk citra terklasifikasi dan data numeric berupaluasan masing-masing kelas sesuai dengan nama masing-masing kelas dengan luasan $\mathrm{km}^{2}$ seperti berikut ini:

Tabel 3.Luas Area TutupanLahan

\begin{tabular}{ccc}
\hline No & kelas & Luas $\left(\mathrm{km}^{2}\right)$ \\
\hline 1 & Badan air & 0,628 \\
2 & bangunan & 102,97 \\
3 & sawah & 320,22 \\
4 & vegetasi & 44,11 \\
\hline
\end{tabular}

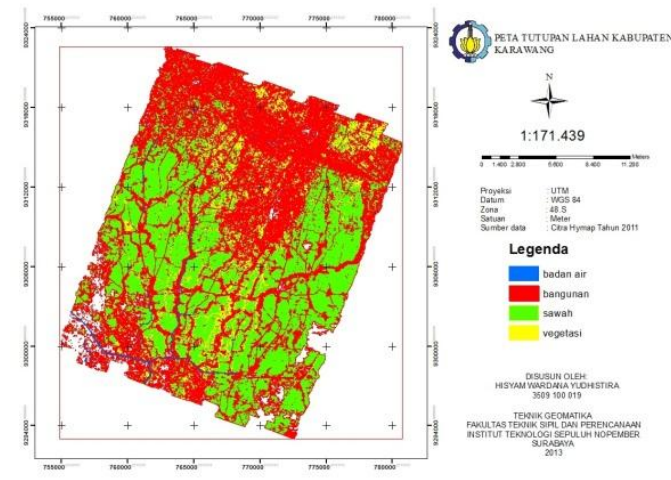

Gambar 5. Peta Tutupan Lahan kabupaten Karawang

E. Intersect Untuk Menggabungkan Hasil Pengolahan Index Vegetasi Dengan Hasil Klasifikasi Supervised

Berikut adalah hasil peta tutupan lahan sawah yang dihasilkan dari pengolahan index vegetasi yang dimintersect dengan hasil pengolahan klasifikasi supervised:

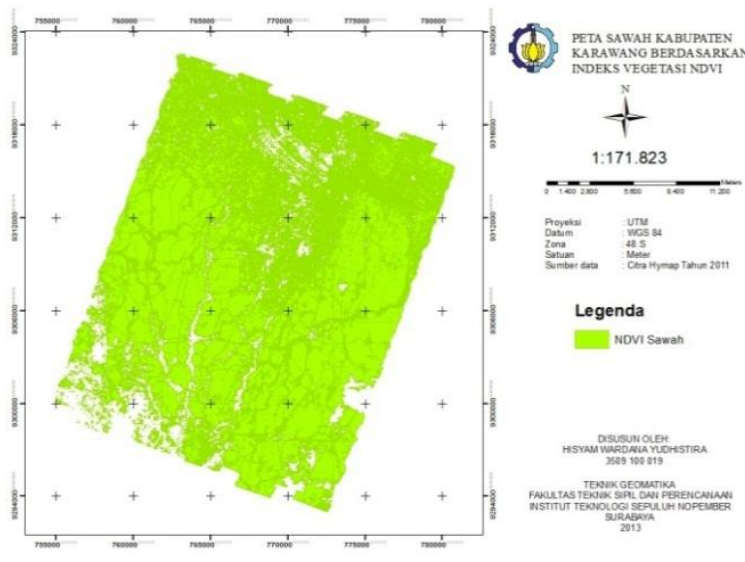

Gambar 6.Peta Tutupan Lahan sawah NDVI

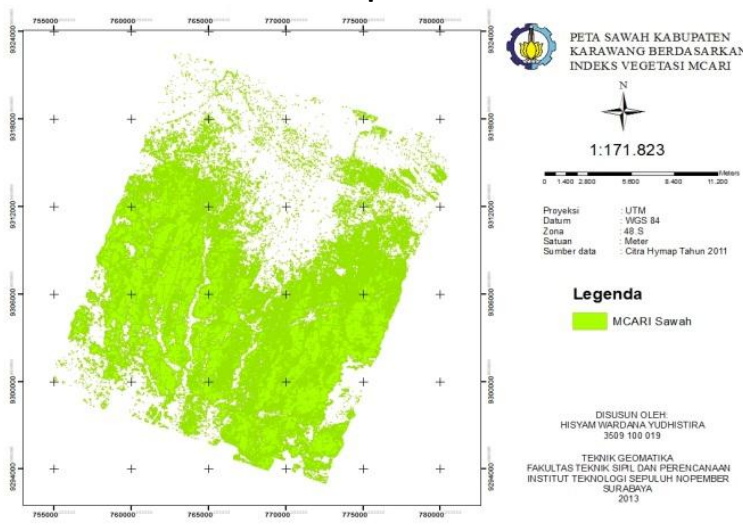

Gambar7. Peta Tutupan Lahan Sawah MCARI

F. Uji Ketelitian Klasifikasi

Uji ketelitian dilakukan untuk mengetahui ketelitian hasil klasifikasi, metode yang digunakan untuk perhitungan adalah confusion matrix Berikut merupakan hasil perhitungan confusion matrix klasifikasi terbimbing tutupan lahan menggunakan perangkat lunak Envi 4.6.1

\section{Tabel 4.Hasil Uji Klasifikasi}

\begin{tabular}{cccccccccc}
\hline $\begin{array}{c}\text { kel } \\
\text { as }\end{array}$ & $\begin{array}{c}\text { ban } \\
\text { gun } \\
\text { an }\end{array}$ & $\begin{array}{c}\text { sa } \\
\text { wa } \\
\text { h }\end{array}$ & $\begin{array}{c}\text { bad } \\
\text { an } \\
\text { air }\end{array}$ & $\begin{array}{c}\text { veg } \\
\text { eta } \\
\text { si }\end{array}$ & $\begin{array}{c}\text { to } \\
\text { ta } \\
\text { l }\end{array}$ & $\begin{array}{c}\text { omi } \\
\text { si }\end{array}$ & MA & $\%$ \\
$\begin{array}{c}\text { bangu } \\
\text { nan }\end{array}$ & 10 & 0 & 0 & 0 & $\begin{array}{c}1 \\
0\end{array}$ & 0 & 1 & 100 \\
sa & & & & & & & & \\
wa & 0 & 10 & 0 & 2 & 1 & 2 & 0,7142 & 71 \\
h & & & & & 2 & & 85714 & 428 \\
bad & & & & & & & & 6 \\
an & 0 & 0 & 8 & 0 & 8 & 0 & 1 & 100 \\
air & & & & & & & & \\
\hline
\end{tabular}




\begin{tabular}{ccccccccc}
\hline $\begin{array}{c}\text { veg } \\
\text { eta }\end{array}$ & 2 & 0 & 0 & 11 & 1 & 2 & 0,7333 & $\begin{array}{c}73, \\
\text { si }\end{array}$ \\
& & & & & 3 & & 33333 & 33 \\
tot & 12 & 10 & 8 & 13 & 4 & 4 & 0,9069 & 90, \\
al & & & & & 3 & & 76744 & 697 \\
& & & & & & & & 7 \\
ko & & & & & & & & \\
mis & 2 & 0 & 0 & 2 & 4 & & & \\
i & & & & & & & & \\
\hline
\end{tabular}

Berdasarkan hasil confusion matrix dengan perangkat Lunak Envi 4.6.1 mendapatkan tingkat ketelitian sebesar 90,69\% dan nilai kesalahan sebesar 9,31\%. Menurut Gallego (1995) dan Sushil Pradan (1999) tingkat ketelitian analisis citra satelit untuk luas areal lahan pertanian diatas $70 \%$ dianggap sudah cukup baik (acceptable result), disbanding penelitian yang dilakukan oleh Harnug pada tahun 2012 yang uji ketelitiannya 84,49\%.

Dari hasil yang didapat bahwa bangunan dan badan air memiliki tingkat ketelitian yang tertinggi yaitu $100 \%$ dan selanjutnya sawah vegetasi dan sawah masing-masing $73,33 \%$ dan $71,42 \%$ karena telah terjadi perubahanlahan di daerah karawang.

\section{KESIMPULAN dan SARAN}

Berdasarkan hasil penelitian metode klasifikasi supervised dan analisa indeks vegetasi dalam pemetaan tutupan lahan sawah dengan data hiperspektral, maka didapatkan beberapa kesimpulan akhir yaitu:

1. Pemetaan Tutupan Lahan pada area studi Kabupaten Karawang dilakukan dengan menggunakan klasifikasi supervised yang menghasilkan Luasan masing-masing kelas adalah sebagai berikut: badan air sebesar $0,628 \mathrm{~km}^{2}$, sawah sebesar $320,22 \mathrm{~km}^{2}$, vegetasi sebesar $44,11 \mathrm{~km}^{2}$ dan bangunan sebesar $102,97 \mathrm{~km}^{2}$

2. Hasil ketelitian index vegetasi didapat bahwa index vegetasi NDVI lebih baik dibanding index vegetasi MCARI dengan nilai korelasi 0,7871
3. Hasil pengolahan index vegetasi untuk luasan tutupan lahan sawah menggunakan index vegetasi NDVI di dapat lebih luas dengan luas $254,12 \mathrm{~km}^{2}$ yang mendekati dari hasil klasifikasi supervised dengan luas $320,22 \mathrm{~km}^{2}$ dibanding MCARI yang dengan luas 186,76 $\mathrm{km}^{2}$

\section{DAFTAR PUSTAKA}

Barrett and Curtis, 1982 dalam Chwen-Ming Yang et.al, 2004

Lillesand, Thomas.M dan Kiefer, Ralph. W. 1994. Remote Sensing and Image Interpretation Third Edition. New York:John Wiley \& Son, Inc.

Lilesand. T.M., W. Kiefer., Chipman, J.W. 2004. Remote Sensing and Image Interpretation (Fifth Edition). John Wiley \& Sons, Inc., New Work.

Lo, C.P. 1996. Penginderaan Jauh Terapan (Terjemahan). Universitas Indonesia Press, Jakarta.

Notohadiprawiro, Tejoyuwono. 2008. Sawah dalam Tata Guna Lahan. Yogyakarta: Fakultas Pertanian, Universitas Gadjah Mada,.

Purwadhi, Sri Hardiyanti. 2001. Interpretasi Citra Digital. Jakarta: PT. Gramedia Widiarsana Indonesia.

Somantri, Lili. 2009. Teknologi Penginderaan Jauh (Remote Sensing). Geografi, UPI.

Suharyadi. 2001. Penginderaan Jauh untuk Studi Kota. Fakultas Geografi Universitas Gadjah Mada, Yogyakarta.

Sutanto. 1986. Penginderaan Jauh I. Gadjah Mada University Press, Yogyakarta.

Creutzfeldt, B. N. A. 2006. Remote Sensing Based Characterisation of Land Cover and Terrain Properties for Hydrological Modelling in The SemiArid Northeast of Brazil. Postdam: Institut fur Geookologie Universitat Potsdam

Howard, John A. 1996. Penginderaan Jauh Untuk Sumber Daya Hutan, Teori dan Aplikasi. Yogyakarta: Gadjah Mada University Press.

Lillesand, T. M and Kiefer R.W. 1990. Penginderaan Jauh dan Interpretasi Citra. Yogyakarta: Gadjah Mada University Press.

Nagasawa, R., dkk. 2009. Evaluation of ASTER Spectral Bands for Agricultural Land Cover Mapping Using Pixel-Based and Object-Based Classification Approaches. Tottori: United Graduate School of Agricultural Sciences, Faculty of Agriculture, Tottori University, Japan. 